\title{
The Effect of Temperature on Cerebrovascular Resistance and Cerebral Metabolism in the Primate ${ }^{1}$
}

\author{
Steven L. Giannotta, M.D., James E. Raisis, M.D., John E. McGillicuddy, M.D., \\ AND GLENN W. KINDT, M.D.
}

University of Michigan Medical Center, Ann Arbor, Michigan 48109

Submitted for publication August 16, 1977

The protective effect of cerebral hypothermia during cardiac and neurosurgical operative procedures has been repeatedly demonstrated $[8,11,14-17,21,22,26,31]$.

Studies in laboratory animals continue to be carried out in order to define both the cerebral metabolic effects and the useful limits of cerebral hypothermia. Recently selective cerebral cooling has become feasible and has been shown to reduce problems arising from total body hypothermia such as cardiac arrhythmias, bradycardia, hypotension, and acidosis $[1,2$, $5-9,16-18,22,28-32]$. Still many procedural problems remain in totally isolating the cerebral circulation for purposes of regional hypothermia. Early laboratory studies used animals other than primates, and the species differences in the cerebral and extracerebral collateral circulation of these animals led to difficulties with uneven cooling and mixing of warm and cold blood $[1,5-7,10,13-15,17,18,22,25,27$, 32]. Systemic arterial pressure, cerebral blood flow, cerebral perfusion pressure, and arterial blood gases were not always controlled in these studies. Few, if any, systematic studies of cerebral metabolism and vascular resistance in the primate using temperatures varying from profound hypothermia through hyperthermia have been reported.

Our study was undertaken to determine the effect of regional cerebral hypothermia

\footnotetext{
${ }^{1}$ This study was supported by Michigan Heart Association Grant \#341051.
}

on cerebrovascular resistance and cerebral oxygen metabolism in an otherwise normotensive, normothermic primate. The experimental model we utilized was studied systematically through a range of temperatures from 44 to $0^{\circ} \mathrm{C}$ in order to gain a more complete idea of the relationship between temperature and cerebral function.

\section{MATERIALS AND METHODS}

Twelve adult Rhesus monkeys were utilized in the study, each weighing between 5 and $6 \mathrm{~kg}$. Anesthesia was produced using ketamine or phencyclidine hydrochloride. Barbiturates were avoided due to their effects on cerebral metabolism. The animals were artificially ventilated through a tracheostomy at a constant rate and volume of oxygen. Both femoral arteries were isolated and cannulated for constant measurement of arterial pressure (SAP) and for measurement of systemic arterial blood gases by mass spectrometer. Femoral veins were isolated for intravenous infusion of cardiotonic drugs when needed. Each internal and external carotid artery was isolated. A single common carotid artery was cannulated for cerebral perfusion using an interposed shunt with heat exchanger and variable-speed roller pump. Internal carotid blood flow distal to the shunt (CBF) was constantly monitored by electromagnetic flowmeter. Internal carotid artery pressure was continually monitored by a transducer at the carotid bifurcation inserted retrograde through the ipsilateral external carotid artery. Both vertebral arteries were ligated and the op- 


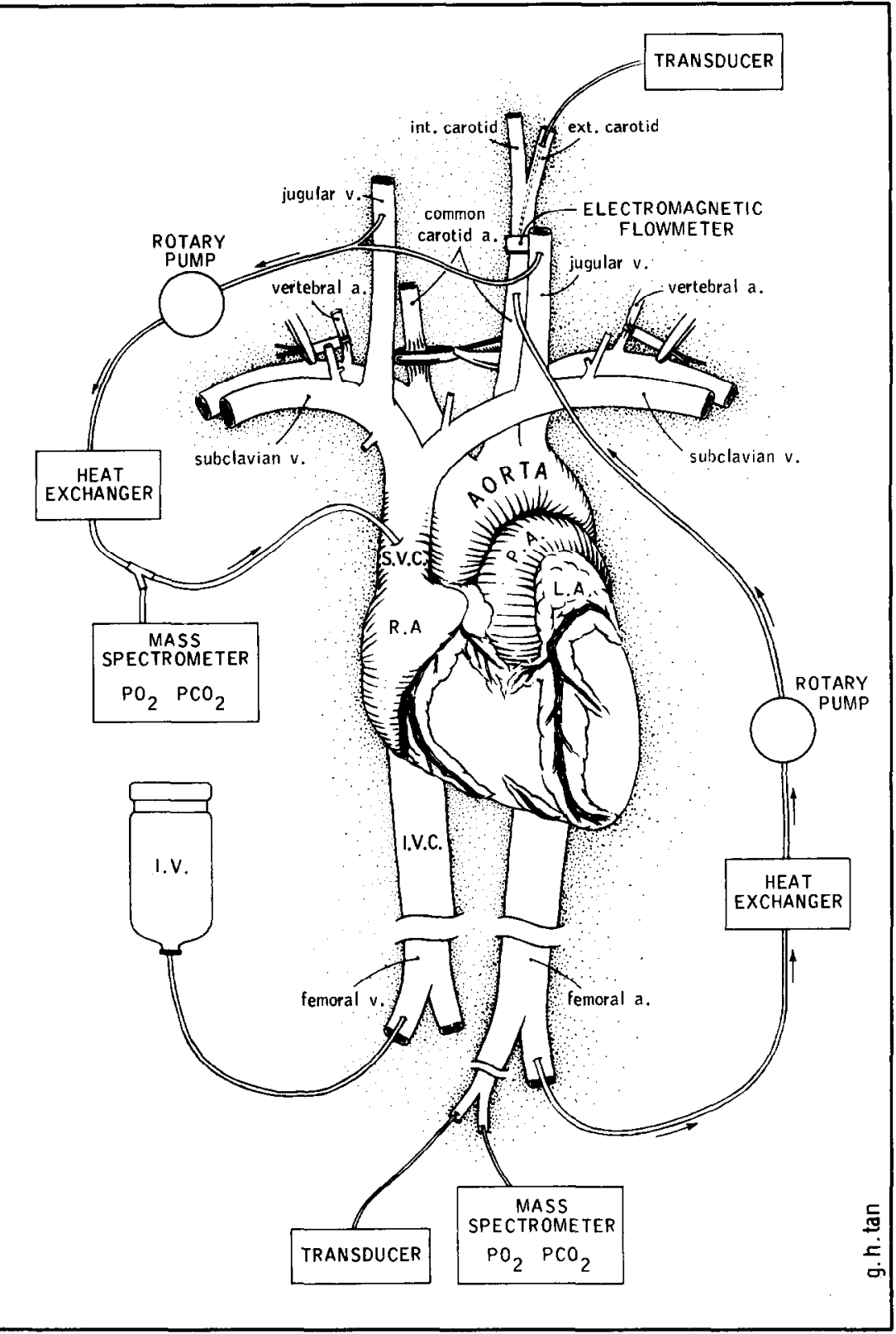

Fig. 1. Animal preparation showing catheter placement for isolated cerebral hypothermia.

posite carotid artery was temporarily occluded to restrict cerebral circulation to the single perfused common carotid artery (Fig. 1).

Venous blood was collected at the jugular bulbs bilaterally, warmed to $37^{\circ} \mathrm{C}$ by a second heat exchanger, and returned to the superior vena cava by way of a second variable-speed roller pump. $p \mathrm{O}_{2}$ and $p \mathrm{CO}_{2}$ levels of rewarmed jugular bulb blood were monitored by mass spectrometer. Esophageal, rectal, and brain temperatures were continually measured by separate thermistor probes. Intracranial pressure (ICP) was measured from the subdural space by the method of Gosch and Kindt [12]. 
Internal carotid artery flow and therefore cerebral blood flow (CBF) was kept constant at $30 \mathrm{ml} / \mathrm{min}(5-6 \mathrm{ml} / \mathrm{min} / \mathrm{kg})$ while brain temperatures were varied systematically through a range of 44 to $0^{\circ} \mathrm{C}$. Extremes of temperature were approached near the end of each experiment. Systemic temperature did not fall below $35^{\circ} \mathrm{C}$. SAP was kept within normal range at low cerebral temperatures by administering norepinephrine. Since ICP remained fairly constant and at low levels throughout the experiment, internal carotid artery pressure was taken to be a reflection of the cerebral perfusion pressure (CPP). CPP and arterial and jugular bulb venous partial pressures of oxygen were recorded at various temperatures. Cerebrovascular resistance (CVR) was determined by dividing the CPP by the $\mathrm{CBF}$ and values were plotted against cerebral temperature (Fig. 2). Cerebral $\mathrm{A}-\mathrm{VO}_{2}$ differences were also calculated and plotted against temperature (Fig. 3).

\section{RESULTS}

By keeping CBF constant at a relatively normal rate, rapid selective cooling of the entire brain was obtained in all 12 animals. When cerebral temperatures fell below $28^{\circ} \mathrm{C}$ systemic hypotension and bradycardia invariably resulted but were controlled easily by infusions of norepinephrine. ICP and

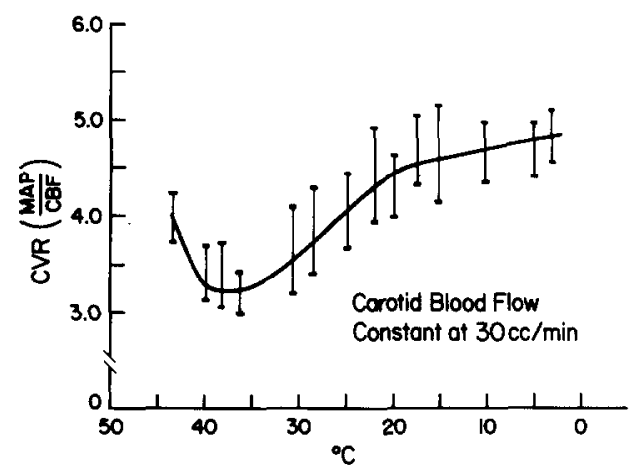

Fig. 2. Effect of temperature on cerebral vascular resistance. Cerebral vascular resistance values from 12 primates are plotted against cerebral temperature in degrees centigrade.

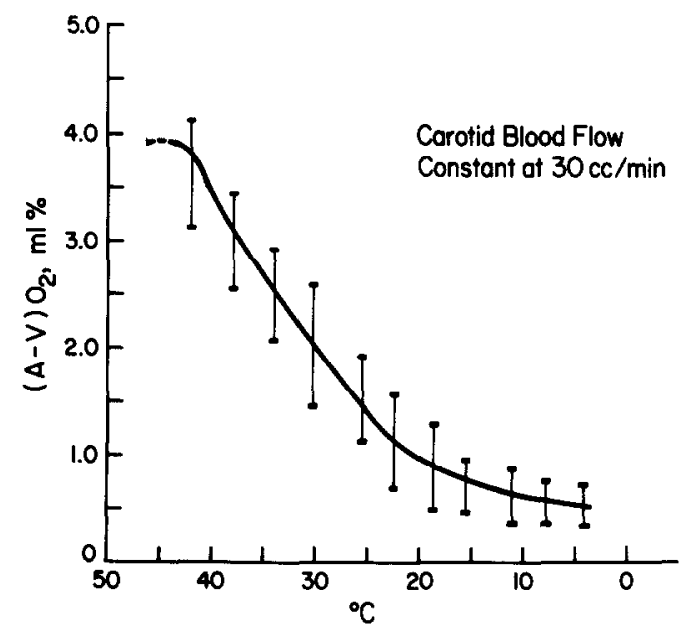

FIG. 3. Effect of temperature on arteriovenous oxygen difference. Arteriovenous oxygen differences from 12 primates are plotted against cerebral temperature in degrees centigrade.

body temperature did not significantly change during this procedure.

In general, CVR varied inversely with brain temperature (Fig. 2). The maximum change in resistance per degree centigrade occurred between 37 and $22^{\circ} \mathrm{C}$. At $22^{\circ} \mathrm{C}$ CVR was on an average of $34 \%$ above values for normal body temperature. At profoundly hypothermic levels $\left(20-3^{\circ} \mathrm{C}\right)$ changes in CVR progressively decreased in magnitude. Upon rewarming a rapid rise in CVR was noted when brain temperature rose above $42^{\circ} \mathrm{C}$.

The cerebral $\mathrm{A}-\mathrm{VO}_{2}$ differences varied directly with brain temperature (Fig. 3). Values ranged from 3.91 to $0.54 \%(\mathrm{v} / \mathrm{v})$. Sample data from a representative primate are shown in Table 1. As temperature fell, $\mathrm{A}-\mathrm{VO}_{2}$ differences decreased. The most profound changes per degree centigrade occurred between 40 and $20^{\circ} \mathrm{C}$ and $\mathrm{O}_{2}$ consumptions decreased by $65 \%$ over this range. Changes in $\mathrm{A}-\mathrm{VO}_{2}$ differences per degree centigrade were notably less between 20 and $3^{\circ} \mathrm{C}$. A fall in $\mathrm{A}-\mathrm{VO}_{2}$ difference was also noted when brain temperature was elevated beyond $42^{\circ} \mathrm{C}$. Also, evidence of irreversible cerebral damage including dilated and fixed pupils 
TABLE 1

Tabulation of A-VO ${ }_{2}$ Differences and CVR from Representative Primate

\begin{tabular}{|c|c|c|}
\hline $\begin{array}{c}\text { Brain Temperature } \\
{ }^{\circ} \mathrm{C}\end{array}$ & $\begin{array}{c}\text { A-VO Difference } \\
\text { Volume } \%\end{array}$ & CVR \\
\hline 42 & 4.53 & 3.46 \\
38 & 3.71 & 3.26 \\
36 & 3.19 & 3.25 \\
34 & 2.60 & 3.28 \\
32 & 2.36 & 3.41 \\
30 & 2.08 & 3.50 \\
28 & 1.94 & 4.59 \\
26 & 1.78 & 3.74 \\
24 & 1.65 & 4.00 \\
22 & 1.56 & 4.27 \\
20 & 1.43 & 4.39 \\
18 & 1.14 & 4.48 \\
16 & .98 & 4.50 \\
14 & .96 & 4.52 \\
10 & .88 & 4.59 \\
7 & .82 & 4.63 \\
5 & .75 & 4.69 \\
3 & .73 & 4.72 \\
\hline
\end{tabular}

unresponsive to further cooling was noted at these high temperatures.

\section{DISCUSSION}

The primate single carotid perfusion model utilized in our experiment functioned well for the purpose of studying cerebral hypothermia. The model maintained a stability that allowed us to study a wider range of temperatures than most other investigators.

The direct relationship between CVR and cerebral temperature demonstrated in this study supports early observations of others using different models $[3,4,9,10,18]$. Lund et al. showed an initial increase in CVR upon isolated cooling of the dog brain followed by fluctuations in resistance which could be influenced by administering $\mathrm{CO}_{2}$ or trimetaphan camphor sulfonate [18]. The lowest brain temperature they achieved was $11^{\circ} \mathrm{C}$. Rosomoff et al. used generalized cooling in dogs and showed an increase in CVR of $160 \%$ at $25^{\circ} \mathrm{C}[24,25]$ Bering et al. also demonstrated this increase in the primate using immersion hypothermia [4]. Narrowing of exposed cerebral cortical vessels was observed and measured by Meyer and Hunter following generalized cooling in cats and primates suggesting vasoconstriction as a mechanism for increasing CVR [21].

Cerebral temperatures in our model were varied to extremes and CVR continued to increase even at temperatures as low as $3^{\circ} \mathrm{C}$. Changes in resistance per degree centigrade were not as marked between 22 and $3^{\circ} \mathrm{C}$ as between 37 and $22^{\circ} \mathrm{C}$. Since intracranial pressure and carotid flow remained constant, these changes most likely represent constriction of cerebral resistance vessels. The mechanism of this vasoconstriction is not known. However, one possibility is that, due to the decreased metabolic rate, local metabolites acting as cerebral vasodilators are not produced in adequate amounts [21]. Also reduction in cerebral temperature could have a direct effect on cerebral vasculature smooth muscle $[19,23]$.

Our findings of reduced $\mathrm{A}-\mathrm{VO}_{2}$ differences at low cerebral temperatures correlate well with the findings of Lougheed and Kahn using generalized hypothermia [17]. They studied dogs at $21^{\circ} \mathrm{C}$ and found successive decreases in $\mathrm{A}-\mathrm{VO}_{2}$ differences. Bering $e t$ al. and Rosomoff $e t$ al. also have confirmed a drop in the $\mathrm{A}-\mathrm{VO}_{2}$ difference with decreasing temperatures $[3,4$, $24,25]$. They did not use perfusion hypothermia and studied temperatures only to $19^{\circ} \mathrm{C}$.

In contrast to some other investigators, we never found an $\mathrm{A}-\mathrm{VO}_{2}$ difference of 0 , even at $3^{\circ} \mathrm{C}[1,32]$. Perhaps this reflects the fact that cerebral blood flow was kept constant in our experiment. This suggests that the brain is able to extract oxygen even at very low temperatures. This is not surprising in view of studies showing increases in lactate-pyruvate ratio as well as oxygen and glucose debt following short periods of ischemia at very low cerebral temperatures [10, 17].

Our data at hypothermic temperatures 
suggest that the brain is able to reversibly adjust CVR and cerebral oxygen consumption to the prevailing brain temperature. However, abrupt changes in CVR and $\mathrm{A}-\mathrm{VO}_{2}$ difference above $42^{\circ} \mathrm{C}$ imply the failure of these adjustments in profound hyperthermia. These changes in hyperthermia were not found to be reversible. This agrees with observations made by Meyer and Handa during experimental hyperthermia [20]. They suggested that increased temperature caused enzymatic damage which may be permanent and may result in decreased cerebral metabolism and cerebral blood flow.

\section{SUMMARY}

Using a primate single carotid perfusion model we studied $\mathrm{CVR}$ and $\mathrm{A}-\mathrm{VO}_{2}$ differences through a wide range of cerebral temperatures. By keeping cerebral blood flow constant and systemic temperature normal, the influence of systemic blood pressure and low cerebral blood flow was avoided. Our data suggest a direct relationship between temperature and CVR as well as oxygen extraction. $\mathrm{A}-\mathrm{VO}_{2}$ differences became less marked below $15^{\circ} \mathrm{C}$ and are probably negligible when considering hypothermia for most clinical uses.

\section{ACKNOWLEDGEMENT}

This study was supported by Michigan Heart Association Grant 341051.

\section{REFERENCES}

1. Adams, J. E., and Pcvchouse, B. C. Regional hypothermia of the brain. Clin. Neurosurg. 6: 104, 1959.

2. Bacalzo, L. V., and Wolfson, S. K. Preferential cerebral hypothermia. Arch. Surg. 103: 393, 1971.

3. Bering, E. A., Jr. Effect of body temperature change on cerebral oxygen consumption of the intact monkey. Amer. J. Physiol. 200: 417, 1958.

4. Bering, E. A., Jr., Taren, J. A., McMurrey, J. D., and Bernhard, W. F. Studies on hypothermia in monkeys. II. The effect of hypothermia on the general physiology and cerebral metabolism of monkeys in the hypothermic state. Surg. Gynecol. Obstet. 102: 134, 1956.
5. Buster, C. D., Pevehouse, B. C., and McCorkle, H. J. Cardiovascular changes associated with selective brain cooling in the dog. Surg. Forum 9: 212,1958 .

6. Chater, N., Adams, J. E., Leake, T. B., and Halliday, B. Cardiovascular effects of local brain stem cooling. Surg. Forum 11: 408, 1960.

7. Connolly, J. E., Harris, E. J., Bruns, D. L., Smith, J. W., Guernsey, J., and Boyd, R. J. An experimental study of the technique and effects of selective brain cooling. Surg. Forum 11: $405,1960$.

8. Demian, Y. K., White, R. J., Yashon, D., and Kretchmer, H. E. Anaesthesia for profound selective autocerebral cooling and circulatory arrest of human brain. Brit. J. Anaesthiol. 42: 900, 1970.

9. Donald, D. E., and White, R. J. Selective brain perfusion in the monkey. Effects of maintained cerebral hypothermia. J. Surg. Res. 2: 213, 1962.

10. Edmunds, L. H., and Folkman, J. Cerebral metabolism during profound hypothermia and circulatory arrest. J. Surg. Res. 1: 201, 1961.

11. Feldman, S. A. Profound hypothermia. Brit. J. Anaesthiol. 43: 244, 1971.

12. Gosch, H. H., and Kindt, G. W. Subdural monitoring of acute increased intracranial pressure. Surg. Forum 23: 405, 1972.

13. Heckers, H., and Gercken, G. Brain metabolism at low temperatures. $J$. Neurochem. 23: 503, 1974.

14. Johnston, J. B., Ushiro, C., Finley, K. H., and Gerbode, F. Profound hypothermia with prolonged circulatory arrest. Thorax 21: 391, 1966.

15. Kramer, R. S., Sanders, A. P., Lesage, A. M., Woodhall, B., and Sealy, W. C. The effect of profound hypothermia on preservation of ATP content during circulatory arrest. J. Thorac. Cardiovasc. Surg. 56: 699, 1968.

16. Kristiansen, K., Krog, J., and Lund, I. Experiences with selective cooling of the brain. Acta Chir. Scand. Suppl. 253: 151, 1960.

17. Lougheed, W. M., and Kahn, D. S. Circumvention of anoxia during arrest of cerebral circulation for intracranial surgery. $J$. Neurosurg. 12: $226,1955$.

18. Lund, I., Johansen, K., Krog, J., and Birkeland, $S$. The change in vascular resistance of the dog's brain on perfusion with cold blood and the modifying effect of $\mathrm{CO}_{2}$ and trimetaphan camphorsulfonate $\left(\right.$ Arfonad $^{\mathrm{R}}$ ). Acta Anaesthesiol. Scand. 2: $149,1958$.

19. Lynch, H. F., and Adolf, E. F. Blood flow in small blood vessels during deep hypothermia. J. Appl. Physiol. 11: 192, 1957.

20. Meyer, J. S., and Handa, J. Cerebral blood flow and metabolism during experimental hyperthermia (fever). Minn. Med. 50: 37, 1967.

21. Meyer, J. S., and Hunter, J. Effects of hypother- 
mia on local blood flow and metabolism during cerebral ischemia and hypoxia. J. Neurosurg. 14: $210,1957$.

22. Parkins, W. M., Jensen, J. M., and Vars, H. M. Brain cooling. The prevention of brain damage during periods of circulatory occlusion in dogs. Ann. Surg. 140: 284, 1954.

23. Rittenhouse, E. A., Ito, C. S., Mohri, H., and Merendino, K. A. Circulatory dynamics during surface induced deep hypothermia and after cardiac arrest for one hour. J. Thorac. Cardiovasc. Surg. 61: 359, 1971.

24. Rosomoff, H. L. Some effects of hypothermia on the normal and abnormal physiology of the nervous system. Proc. Roy. Soc. Med. 49: 358, 1956.

25. Rosomoff, H. L., and Holaday, D. A. Cerebral blood flow and cerebral oxygen consumption during hypothermia. Amer. J. Physiol. 179: 85, 1954.

26. Stone, H. H., Donnelly, C., and Frobese, A. S. The effect of lowered body temperature on the cerebral hemodynamics and metabolism of man. Surg. Gynecol. Obstet. 103: 313, 1956.
27. Tabaddor, K., Gardner, T. J., and Walker, A. E. Cerebral circulation and metabolism at deep hypothermia. Neurology 22: 1065, 1972.

28. White, R. J., Austin, P. E., Austin, J. C., Taslitz, N., and Takoaka, Y. Recovery of the subhuman primate after deep cerebral hypothermia and prolonged ischaemia. Resuscitation 2: 117, 1973.

29. White, R. J., and Donald, D. E. Total Cerebral ischemia and perfusion hypothermia in the dog. Surg. Forum 11: 410, 1960.

30. White, R. J., Massopust, L. A., Wolin, L. R., Taslitz, N., and Yashon, D. Profound selective cooling and ischemia of primate brain without pump or oxygenator. Surgery 66: 224, 1969.

31. Wolfson, S. K., and Selker, R. G. Carotid perfusion hypothermia for brain surgery using cardiac arrest without bypass. J. Surg. Res. 14: 449, 1973.

32. Woodhall, B., Reynolds, D. H., Mahaley, S., Jr., Sanders, A. P. The physiologic and pathologic effects of localized cerebral hypothermia. Ann. Surg. 147: 673, 1958. 